\title{
Uso do subgalato de bismuto como agente hemostático e sua influência no reparo tecidual em cirurgias odontológicas
}

\author{
Use of bismut subgalate as a hemostatic agent and its influence on tissue repair in dental surgerys \\ Uso de subgalato de bismuto como agente hemostático y su influencia en la reparación de tejidos en \\ cirugía dental
}

Recebido: 19/09/2021 | Revisado: 29/09/2021 | Aceito: 02/11/2021 | Publicado: 04/11/2021

Leticia Perez Mazzoni

ORCID: https://orcid.org/0000-0001-6914-5652

Universidade Estadual do Norte do Paraná, Brasil

E-mail: lemazzoni@hotmail.com

Járcio Victorio Baldi

ORCID: https://orcid.org/0000-0003-4893-8279

Universidade Estadual do Norte do Paraná, Brasil

E-mail: jvbaldi@gmail.com

José Sidney Roque

ORCID: https://orcid.org/0000-0001-9065-4064

Universidade Estadual do Norte do Paraná, Brasil

E-mail: jsidneyroque@gmail.com

Luiz Alberto Dib Canonico

ORCID: https://orcid.org/0000-0002-9406-179X

Universidade Estadual do Norte do Paraná, Brasil

E-mail: dentistadib@hotmail.com

Vitor de Toledo Stuani

ORCID: https://orcid.org/0000-0001-5290-7614

Universidade de São Paulo, Brasil

E-mail: vitortoledo@usp.br

Matheus Völz Cardoso

ORCID: https://orcid.org/0000-0002-7609-8003

Universidade de São Paulo, Brasil

E-mail: matheusvolz@usp.br

Gustavo Gonçalves do Prado Manfredi

ORCID: https://orcid.org/0000-0001-9623-9769

Universidade de São Paulo, Brasil

E-mail: gustavo.manfredi@usp.br

Ísis De Fátima Balderrama

ORCID: https://orcid.org/0000-0002-8606-9054

Universidade Estadual Paulista, Brasil

E-mail: if.balderrama@unesp.br

Rafael Ferreira

ORCID: https://orcid.org/0000-0001-5879-2782

Universidade Federal de Mato Grosso do Sul, Brasil

E-mail: Rafael_ferreira@ufms.br

\begin{abstract}
Resumo
Durante os procedimentos cirúrgicos odontológicos, há o risco de ocorrerem episódios hemorrágicos que podem estar associados a fatores locais e/ou sistêmicos. Um dos materiais que podem ser utilizados como hemostático local é o subgalato de bismuto (SB). O objetivo desse estudo foi avaliar o uso do SB em cirurgias odontológicas, abordando sua eficácia como substância hemostática. Para a revisão de literatura, foram pesquisados artigos nas bases de dados SciELO, PubMed e Scopus, e selecionados artigos pré-clínicos e clínicos que discorressem sobre a influência do subgalato de bismuto em cirurgias odontológicas. O subgalato de bismuto é um metal pesado e insolúvel em água que pode ser utilizado por via oral ou aplicado topicamente. Apresenta eficácia na hemostasia de áreas doadoras palatais, em cirurgias de extrações dentárias e até mesmo em pacientes dialisados. Apesar da sua efetividade como agente hemostático, ele pode provocar alterações no reparo tecidual, como demonstram alguns estudos in vivo na medicina. Esses estudos demonstram efeitos deletérios sobre o reparo tecidual advindos do SB, limitando seu emprego a casos específicos a fim de evitar os riscos de hemorragia trans ou pós-operatória. Já em estudos na área odontológica, tais efeitos não foram observados. Portanto, apesar da literatura demonstrar vantagens no uso do SB como agente
\end{abstract}


hemostático, vale ressaltar que os estudos clínicos em humanos não são numerosos, havendo necessidade de mais pesquisas para verificar sua eficácia clínica e influência sobre o reparo tecidual na busca de protocolos clínicos efetivos. Palavras-chave: Subgalato de Bismuto; Hemostáticos; Palato.

\begin{abstract}
During dental surgical procedures, there is a risk of bleeding episodes that may be associated with local and / or systemic factors. The bismuth subgalate (BS) may be used as a local hemostatic. The aim of this study was to evaluate the use of BS in dental surgery, addressing its effectiveness as a hemostatic substance. For the literature review, articles were searched in the SciELO, PubMed and Scopus databases. Pre-clinical and clinical articles that discuss BS influence in dental surgeries were selected. BS is a heavy metal and insoluble in water and can be used orally or topically. It has effectiveness in hemostasis of palatal donor areas, in dental extraction surgeries and even in dialysis patients. Studies carried out in humans and animals have shown deleterious effects on tissue repair using BS. Despite its effectiveness as a hemostatic agent, it can cause changes in tissue repair, limiting its use to specific cases in order to avoid risks of trans or postoperative hemorrhage. Therefore, although the literature demonstrates advantages in the use of BS as a hemostatic agent, there are not many clinical studies. Further research is needed in order to analyze the clinical efficiency on tissue repair.
\end{abstract}

Keywords: Bismuth; Hemostatics; Palate.

\title{
Resumen
}

Durante los procedimientos quirúrgicos dentales, existe el riesgo de episodios hemorrágicos que pueden estar asociados con factores locales y / o sistémicos. Uno de los materiales que se puede utilizar como hemostático local es el subgalato de bismuto (SB). El objetivo de este estudio fue evaluar el uso de SB en cirugías dentales, abordando su efectividad como sustancia hemostática. Para la revisión de la literatura, se buscaron artículos en las bases de datos SciELO, PubMed y Scopus, y se seleccionaron artículos preclínicos y clínicos que discutían la influencia del subgalato de bismuto en las cirugías dentales. El subgalato de bismuto es un metal pesado insoluble en agua que puede tomarse por vía oral o aplicarse tópicamente. Es eficaz en la hemostasia de zonas donantes palatinas, en cirugías de extracción de dientes e incluso en pacientes en diálisis. A pesar de su eficacia como agente hemostático, puede provocar cambios en la reparación de tejidos, como demuestran algunos estudios in vivo en medicina. Estos estudios demuestran efectos deletéreos sobre la reparación tisular derivados del SB, limitando su uso a casos específicos para evitar el riesgo de hemorragia trans o postoperatoria. En estudios en el campo dental, no se observaron tales efectos. Por tanto, aunque la literatura demuestra ventajas en el uso de SB como agente hemostático, es de destacar que los estudios clínicos en humanos no son numerosos, requiriendo más investigación para verificar su eficacia clínica e influencia en la reparación tisular en la búsqueda de protocolos clínicos efectivos.

Palabras clave: Subgalato de bismuto; Hemostáticos; Paladar.

\section{Introdução}

A hemorragia é a perda de sangue para um órgão interno ou ao meio externo que pode ocorrer por fatores locais ocasionados por rupturas ou laceração de vasos sanguíneos, enfermidades sistêmicas como trombocitopenia, hemofilia, anemia, doença de Willebrand (Dym \& Ogle, 2004), coagulopatias adquiridas devido ao uso de anticoagulantes como varfarina e heparina (Levine, Raskob, Landefeld, \& Hirsh,, 1995) ou também pelo uso contínuo de anti-inflamatórios não esteroidais e derivados do ácido acetilsalicílico (Peterson, 2000).

A complicação hemorrágica pode ocorrer em qualquer tipo de cirurgia odontológica, especialmente em cirurgias periodontais. Nas cirurgias de enxertos de tecido mole, a remoção do tecido na região doadora e a confecção do leito receptor, podem levar a quadros hemorrágicos. A região do palato é uma das áreas mais utilizadas para a doação de tecido a ser enxertado e também uma região temerosa ao clínico (Holck, Foster, Dutton, \& Dillon, 1999) pela presença da artéria palatina.

As complicações hemorrágicas podem ser classificadas como primárias ou secundárias. As primárias acontecem durante ou imediatamente após os procedimentos cirúrgicos e denotam um prognóstico favorável quando o cirurgião-dentista realiza um manejo adequado da situação. Já as hemorragias secundárias ou tardias, ocorrem horas ou, na maioria das vezes, dias após a cirurgia, tendo relação com distúrbios hematológicos que foram ou não diagnosticados previamente na anamnese (de Campos, Furlaneto \& Buischi, 2019).

Na prática odontológica, pacientes com transtornos de coagulação ou riscos de hemorragia requerem cuidados especiais (Barbosa et al., 2020). Uma anamnese detalhada, associada a exames físicos e complementares como os exames de sangue, 
podem auxiliar na detecção de coagulopatias. É muito importante que o cirurgião-dentista conheça as manobras hemostáticas para que possa fornecer um tratamento adequado ao paciente (Quintero Parada, Sabater Recolons, Chimenos Kustner, \& López López, 2004), assim como um elevado grau de conhecimento anatômico da região a ser operada e das substâncias prócoagulantes que possam ser utilizadas (Peterson, 2000), como o uso do ácido tranexâmico (de Souza Pinheiro, Veloso, Andrade \& Oliveira, 2021)

Devido às suas propriedades, o subgalato de bismuto (SB) pode ser utilizado como agente hemostático tópico (Subgalato de bismuto 2016). Este agente apresenta importância na redução das complicações trans e pós-operatórias, além de favorecer a realização de procedimentos com menores taxas de complicações, resultando em maior tranquilidade para o paciente e profissional (Kim, Tramontina, Papalexiou \& Luczyszyn, 2010). Diante do exposto, esse estudo tem como objetivo realizar uma revisão de literatura sobre a utilização do SB em cirurgias odontológicas e sua influência no reparo tecidual.

\section{Metodologia}

\section{Desenho do estudo}

Trata-se de uma revisão integrativa de literatura (Mendes, Silveira \& Galvão, 2008) que foi estruturada de acordo com as seguintes perguntas: "O uso do SB pode auxiliar na hemostasia tecidual em cirurgias odontológicas? Seu uso pode afetar no reparo tecidual". Portanto, esse estudo tem como objetivo avaliar os efeitos homeostáticos e a influência sobre o reparo tecidual ao se utilizar o SB para promoção de homeostasia em diferentes usos em cirurgias odontológicas.

\section{Estratégia de Busca}

Para a realização da revisão de literatura, foram pesquisados artigos nas bases de dados SciELO, PubMed e busca manual de acordo com a lista de referências dos artigos em outras bases de dados (como o Google Acadêmico). As palavraschave utilizadas foram: "bismuth subgallate", "hemostatic agent", "dental surgery", "palatal donor sites", "hemostasis surgical", "surgical procedures, operative", "hemostatic techniques", com "and" como ferramentas integrativas de busca. Para a seleção dos artigos, não houve restrição quanto ao tempo de publicação. Foram selecionados estudos publicados até setembro de 2021.

\section{Critérios de Inclusão}

Como critério de inclusão, foram selecionados artigos que buscassem compreender a influência do uso tópico do SB em cirurgias odontológicas. Portanto, foram selecionados estudos prospectivos, retrospectivos, caso-controle, transversal e relatos de casos. Além do mais, para favorecer a compreensão da influência do SB sobre o reparo tecidual, foram selecionados também estudos clínicos em animais.

\section{Critérios de Exclusão}

Foram excluídos os estudos que não utilizassem o SB para fins odontológicos ou que realizassem seu uso de forma sistêmico, além dos artigos que não contemplasse a temática abordada.

\section{Análise estatística}

Por se tratar de uma revisão integrativa da literatura foram realizadas uma avaliação descritiva e comparativa dos artigos selecionados.

\section{Resultados}

Após cruzamento dos descritores, foram encontrados 89 artigos. Desses, 38 eram potencialmente elegíveis, sendo que 20 apresentavam-se duplicados e 2 estudos foram excluídos por aplicação na área médica (cirurgias otorrinolaringológicas), chegando ao total de 16 artigos que foram lidos de forma integral. Após essa análise, 5 estudos foram excluídos pelos critérios 
Research, Society and Development, v. 10, n. 14, e350101420791, 2021

(CC BY 4.0) | ISSN 2525-3409 | DOI: http://dx.doi.org/10.33448/rsd-v10i14.20791

de exclusão devido aplicação extra oral (como análise em dorso de ratos). A distribuição geral da seleção dos artigos pode ser observada na Figura 1.

Figura 1: Fluxograma da seleção dos artigos incluídos nessa revisão.

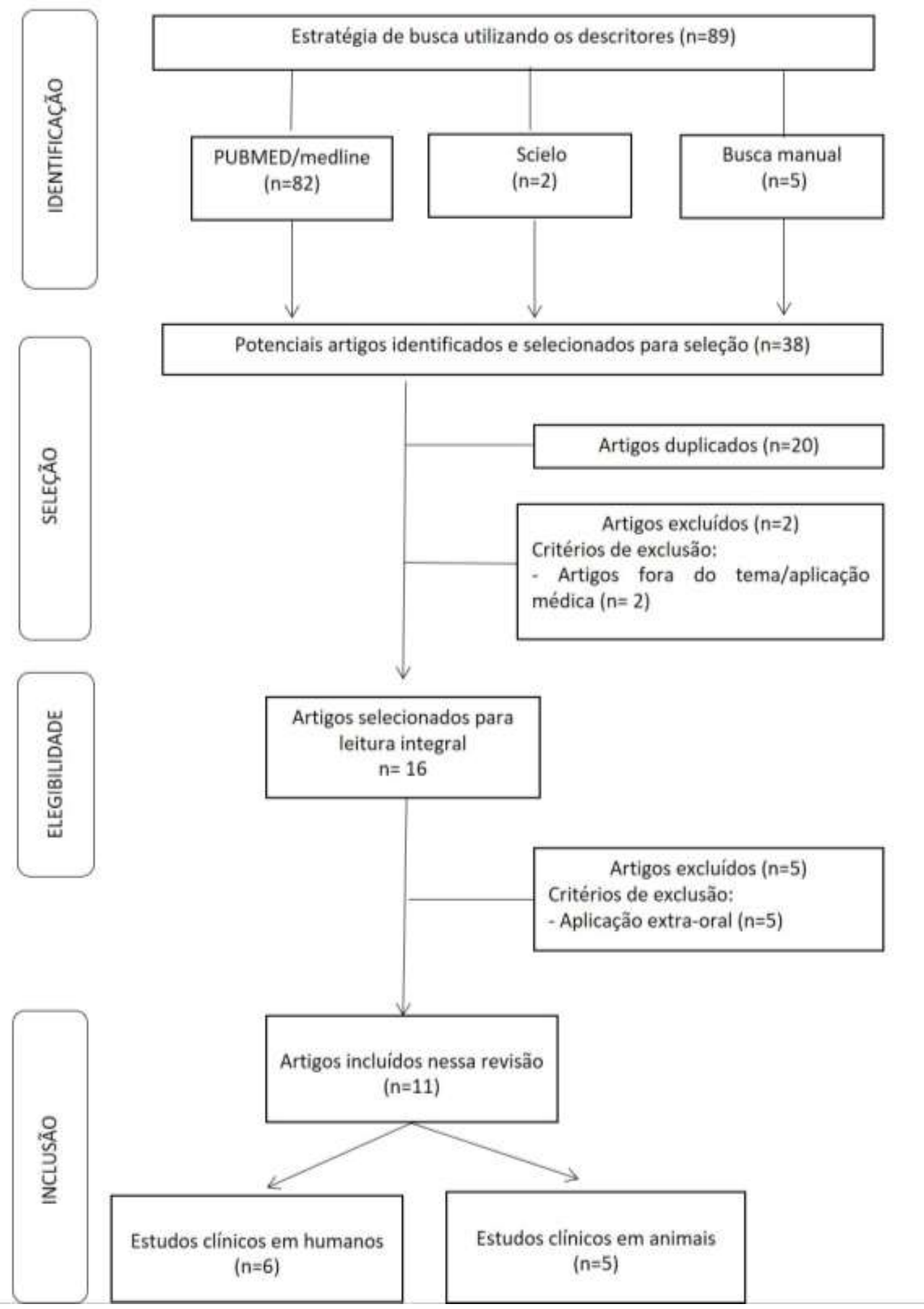

Fonte: Autores. 
O SB (C7H5BiO6), comercialmente conhecido como Dermatol®, é um sal de metal pesado, pouco adsorvido (Arroyo Júnior et al., 2004), insolúvel em água, álcool, clorofórmio e éter (O'Neil, Smith, Heckelman, \& Budavari, 2001), de coloração amarelada e que apresenta propriedades adstringentes e hemostáticas (Brasileiro, Lee \& Rapport., 2006). A sua fabricação é resultado da dissolução do subnitrato de bismuto em ácido acético diluído, precipitando o composto com ácido gálico (Kim et al., 2010).

Sua indicação na área médica é bastante ampla, recomendando seu uso em casos de eczemas com secreção volumosa, queimaduras, escoriações e feridas (Subgalato de bismuto, 2016). É também indicado para o alívio do odor das fezes e flatulência em pacientes submetidos à cirurgia bariátrica e com Síndrome do Intestino irritável (Subgalato de bismuto 2016). Sua utilização e aplicabilidade na Medicina ocorrem há três séculos como emoliente, adstringente e antisséptico (Kim et al., 2012). Na odontologia é utilizado como agente hemostático em casos de cirurgias periodontais (Kim et al., 2010).

$\mathrm{Na}$ odontologia, sua maior aplicabilidade acontece na forma tópica, valendo-se de suas propriedades como agente adstringente, homeostático com propriedades absorventes (Subgalato de bismuto, 2016) e, portanto, por meio da ativação do fator XII ele acelera a via intrínseca da cascata de coagulação (Thorisdottir, Ratnoff, \& Maniglia, 1988; Kim et al., 2010). Os estudos decorrentes da busca na literatura referentes ao SB podem ser visualizados nas tabelas 1 e 2.

A contra indicação explícita para o seu uso está em casos de reação de hipersensibilidade a esse composto. Foram relatados na literatura alguns casos de intoxicação pelo SB quando ingerido indiscriminadamente via oral (Thorisdottir et al. 1988; Sampognaro, Richie, Blanc \& Keenan, 2017). Além disto, também se deve ter um grande cuidado quanto a aspiração do produto na forma em pó. As partículas do produto podem gerar um quadro de pneumonite intersticial reativa e o desenvolvimento de pneumonias bacterianas (Cozzi et al., 1992). Como efeitos colaterais, apresenta pigmentação escurecida na língua e risco de reação de corpo estranho, podendo resultar em pneumonia aguda (Liu et al., 2019). 
Tabela 1: Revisão de literatura com artigos abordando o uso do subgalato de bismuto em estudos clínicos em humanos.

\begin{tabular}{|c|c|c|c|c|}
\hline Autores & Objetivo & Materiais e métodos & Resultados & Conclusão \\
\hline $\begin{array}{l}\text { Loya et al. } \\
\text { (2003) }\end{array}$ & $\begin{array}{l}\text { Avaliar a eficácia } \mathrm{e} \\
\text { segurança do SB e do } \\
\text { subsalicilato de bismuto } \\
\text { como agentes hemostáticos }\end{array}$ & $\begin{array}{l}\text { Foram incluídos } 71 \text { pacientes com indicação de } \\
\text { extração cirúrgica dos } 4 \text { terceiros molares, todos } \\
\text { foram submetidos com cada uma das substâncias, } \\
\text { totalixando } 284 \text { extrações. Foram aplicados de } \\
\text { forma aleatórias a substância hemostática (SB ou } \\
\text { SB') em um dos alvéolos e a substância controle } \\
\text { foi colocada no alvéolo contralateral. }\end{array}$ & $\begin{array}{l}\text { O grupo tratado com SB obteve } 1,97 \text { min. } \\
\text { como tempo médio de sangramento nas } \\
\text { extrações, e o controle } 3,52 \text { min., } \\
\text { observando a diferença estatisticamente } \\
\text { significante }(\mathrm{F}=146,62 ; \mathrm{p}<0,05) \text {. }\end{array}$ & $\begin{array}{l}\text { O SB e o SB' são seguros e eficazes como } \\
\text { agentes hemostáticos, sem apresentar } \\
\text { efeitos adversos. }\end{array}$ \\
\hline $\begin{array}{l}\text { Manterola e } \\
\text { Smerilli } \\
(\text { (2007) }\end{array}$ & $\begin{array}{l}\text { Avaliar o uso de SB como } \\
\text { método hemostático local em } \\
\text { extrações realizadas em } \\
\text { pacientes dialisados. }\end{array}$ & $\begin{array}{l}\text { Foram avaliados } 83 \text { pacientes dialisados, sendo } \\
32 \text { do gênero feminino e } 51 \text { do gênero masculino, } \\
\text { com idade entre } 27 \text { e } 86 \text { anos de idade, que } \\
\text { necessitavam de extração dentária. }\end{array}$ & $\begin{array}{l}\text { De } 16 \text { extrações que não foram utilizadas } \\
\text { SB no intraoperatório, houve } 5 \\
\text { hemorragias. Já em } 20 \text { extrações que foi } \\
\text { utilizado o SB no intraoperatório não } \\
\text { houve hemorragias pós-operatórias. }\end{array}$ & $\begin{array}{l}\text { É aconselhável utilizar o SB } \\
\text { rotineiramente nesses pacientes como } \\
\text { método hemostático para prevenir } \\
\text { possíveis hemorragias após as cirurgias. }\end{array}$ \\
\hline $\begin{array}{l}\text { Kim } \\
\text { et al. } \\
(\mathbf{2 0 1 0})\end{array}$ & $\begin{array}{l}\text { Avaliar o uso de uma pasta de } \\
\text { SB como agente hemostático } \\
\text { na área doadora palatina de } \\
\text { enxerto gengival livre. }\end{array}$ & $\begin{array}{l}2 \text { grupos com } 10 \text { pacientes cada em que foi } \\
\text { aplicado o SB ou CS nas regiões palatinas } \\
\text { doadores de enxerto gengival. Avaliação pela } \\
\text { mensuração do tempo de hemostasia e } \\
\text { sangramento tardio. }\end{array}$ & $\begin{array}{l}\text { A pasta de SB diminui o tempo de } \\
\text { sangramento quando comparado com a } \\
\text { pressão de gaze umedecida. Não houve } \\
\text { diferença quanto ao controle do } \\
\text { sangramento tardio. }\end{array}$ & $\begin{array}{l}\text { O uso de SB como agente hemostático } \\
\text { tópico pode ser uma boa opção para a } \\
\text { proteçãa de áreas cruentas palatinas de } \\
\text { áreas doadoras de enxerto gengival livre. }\end{array}$ \\
\hline $\begin{array}{l}\text { Pires } \\
\text { et al. } \\
(\mathbf{2 0 1 6})\end{array}$ & $\begin{array}{l}\text { Avaliar o uso do SB como } \\
\text { agente hemostático pós } \\
\text { exérese de hiperplasia } \\
\text { papilomatosa no palato. }\end{array}$ & $\begin{array}{l}\text { Paciente do sexo feminino, apresentou diversas } \\
\text { pápulas no palato duro, caracterizada como } \\
\text { hiperplasia papilomatosa. Após o procedimento } \\
\text { cirúrgico foi colocado SB a } 100 \% \text {, em pó. }\end{array}$ & $\begin{array}{l}\text { Observou-se um bom estado de } \\
\text { cicatrização tecidual no pós-operatório e } \\
\text { não houve complicações. }\end{array}$ & $\begin{array}{l}\text { O SB foi efetivo na homeostasia da região } \\
\text { palatina, com ausência de efeitos } \\
\text { colaterais. }\end{array}$ \\
\hline $\begin{array}{l}\text { Baldelomar } \\
\text { Carballo e } \\
\text { Guerrero } \\
\text { Petterson } \\
\text { (2020) } \\
\end{array}$ & 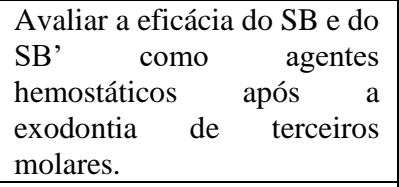 & $\begin{array}{l}\text { Foram incluídos } 40 \text { pacientes, foram realizadas } \\
80 \text { extrações. } 30 \text { alvéolos receberam o SB, } 30 \\
\text { receberam SB' e } 20 \text { (grupo controle) receberam } \\
\text { CS. }\end{array}$ & $\begin{array}{l}\text { O SB teve } 31,25 \% \text { em tempo de } \\
\text { sangramento de } 1 \text { a } 3 \text { min. e de } 30 \% \text { o } \\
\text { tempo de coagulação entre } 1 \text { a } 3 \text { min. }\end{array}$ & $\begin{array}{l}\text { O subgalato de bismuto deve ser a droga } \\
\text { de primeira escolha, por ter o menor tempo } \\
\text { de sangramento e coagulação }\end{array}$ \\
\hline $\begin{array}{l}\text { Puia } \\
\text { et al. } \\
(\mathbf{2 0 2 0})\end{array}$ & $\begin{array}{l}\text { Comparar a eficácia de } 3 \\
\text { agentes hemostáticos locais } \\
\text { para extrações dentárias, sem } \\
\text { suspender o anticoagulante } \\
\text { com antagonista da vitamina } \\
\text { K. }\end{array}$ & $\begin{array}{l}\text { O estudo incluiu } 240 \text { pacientes que continuaram } \\
\text { tomando o anticoagulante normalmente, após as } \\
\text { extrações foi aplicado aleatoriamente } S B \text {, adesivo } \\
\text { tecidual de fibrina (ATF) ou colágeno } \\
\text { microfibrilar (CM). }\end{array}$ & $\begin{array}{l}\text { Não houve complicação no grupo SB, e } \\
\text { apenas uma complica̧ão no grupo ATF, } \\
\text { já o grupo CM } 12,5 \% \text { dos pacientes } \\
\text { sofreram sangramento pós-operatório. }\end{array}$ & $\begin{array}{l}\text { O SB conferiu eficácia clínica no controle } \\
\text { do sangramento pós-operatório em } \\
\text { pacientes anticoagulados. }\end{array}$ \\
\hline
\end{tabular}

Legenda: SB, subgalato de bismuto; CS, cloreto de sódio (“soro fisiológico"); ATF, adesivo tecidual de fibrina; CM, colágeno microfibrilar; SB', subsalicilato de bismuto. Fonte: Autores.

Com base nas informações presentes na Tabela 1, os estudos clínicos reportam os resultados positivos em relação ao uso do SB como agente hemostático. 
Tabela 2: Revisão de literatura com artigos abordando o uso do subgalato de bismuto em animais.

\begin{tabular}{|c|c|c|c|c|}
\hline Autores & Objetivo & Materiais e métodos & Resultados & Conclusão \\
\hline $\begin{array}{l}\text { Tramontina } \\
\text { et al. (2002) }\end{array}$ & $\begin{array}{l}\text { Avaliar o efeito do SB no } \\
\text { processo de reparação tecidual. }\end{array}$ & $\begin{array}{l}\text { Foram realizadas duas feridas padronizadas no } \\
\text { dorso de } 40 \text { ratos Wistar, sendo tratadas com SB } \\
\text { ou solução fisiológica } 0,9 \% \text {. Foram avaliados } \\
\text { em } 5 \text { períodos }(1,4,7,11 \text { e } 18 \text { dias). }\end{array}$ & $\begin{array}{l}\text { Histologicamente e macroscopicamente não } \\
\text { houve diferença significativa entre os grupos. } \\
\text { Histometricamente, a diferença estatística foi } \\
\text { favorável para as feridas tratadas com SB. }\end{array}$ & $\begin{array}{l}\text { O SB não interferiu na qualidade } \\
\text { do processo de reparação, } \\
\text { podendo ser indicado como } \\
\text { hemostático. }\end{array}$ \\
\hline $\begin{array}{l}\text { Puia } \\
\text { et al. } \\
(2009)\end{array}$ & $\begin{array}{l}\text { Avaliar o efeito do SB no } \\
\text { reparo ósseo após extração. }\end{array}$ & $\begin{array}{l}40 \text { ratos Wistar foram submetidos à extração } \\
\text { dentária. Foi feita avaliação histológica, } \\
\text { histomorfométrica e radiográfica em } 3 \text { períodos } \\
\text { ( } 7,14 \text { e } 30 \text { dias). }\end{array}$ & $\begin{array}{l}\text { As análises não mostraram diferenças } \\
\text { estatisticamente significantes entre os grupos. }\end{array}$ & $\begin{array}{l}\text { O SB não interferiu no reparo } \\
\text { ósseo pós-extração. }\end{array}$ \\
\hline $\begin{array}{l}\text { Kim } \\
\text { et al. } \\
(2012)\end{array}$ & $\begin{array}{l}\text { Avaliar o processo de } \\
\text { recuperação precoce das feridas } \\
\text { palatinas de cães } \\
\text { utilizando o SB. }\end{array}$ & $\begin{array}{l}5 \text { cães saudáveis foram submetidos a } 8 \text { biópsias } \\
\text { na mucosa mastigatória palatina e posterior } \\
\text { avaliaçãa histológica após aplicação do SB. }\end{array}$ & $\begin{array}{l}\text { Nenhuma diferença estatisticamente } \\
\text { significativa foi encontrada em } 21 \text { dias. }\end{array}$ & $\begin{array}{l}\text { O SB não interferiu no reparo } \\
\text { tecidual da mucosa mastigatória } \\
\text { palatal em cães. }\end{array}$ \\
\hline $\begin{array}{l}\text { Couto } \\
\text { et al. } \\
(\mathbf{2 0 1 6})\end{array}$ & $\begin{array}{l}\text { Avaliar o efeito do SB } \\
(0,5 \mathrm{mg}) \text { ou do CS }(0,9 \%) \text { em } \\
\text { feridas na mucosa bucal de } \\
\text { ratos. }\end{array}$ & $\begin{array}{l}\text { Foram induzidas lesões na mucosa bucal de } 60 \\
\text { ratos que foram tratados com SB ou CS. Foi } \\
\text { feita avaliação da neogênese de vasos. }\end{array}$ & $\begin{array}{l}\text { O uso do SB apresentou maior reação } \\
\text { inflamatória. Houve aumento da proliferação } \\
\text { de vasos no grupo sem uso do SB. }\end{array}$ & $\begin{array}{l}\text { O SB teve influência negativa no } \\
\text { processo de cicatrização. }\end{array}$ \\
\hline $\begin{array}{l}\text { Luzzi } \\
\text { et al. } \\
(2018)\end{array}$ & $\begin{array}{l}\text { Avaliar o reparo da mucosa } \\
\text { palatina em ratos após o uso do } \\
\text { SB associado ao gel de FD. }\end{array}$ & $\begin{array}{l}75 \text { ratos foram submetidos a feridas no palato e } \\
\text { tratados com CS, gel de FD ou gel de FD + SB. } \\
\text { A análise histológica foi feita em } 5 \text { períodos ( } 3 \text {, } \\
7,14,30 \text { e } 60 \text { dias). }\end{array}$ & $\begin{array}{l}\text { A presença de coágulo foi menor aos } 3 \text { e } 7 \\
\text { dias no grupo FD. O grupo CS teve maior } \\
\text { presença de necrose em relação aos grupos } \\
\text { FD e FD + SB. }\end{array}$ & $\begin{array}{l}\text { A aplicação tópica da FD } \\
\text { promoveu um fechamento } \\
\text { epitelial mais rápido e sua } \\
\text { utilização (isolada ou associada } \\
\text { ao SB) não interferiu no reparo } \\
\text { epitelial. }\end{array}$ \\
\hline
\end{tabular}

Legenda: SB, subgalato de bismuto; CS, cloreto de sódio (“soro fisiológico”); FD, fibrinolisina, desoxirribonuclease. *Artigos semelhantes, porém em línguas diferentes. Fonte: Autores.

Na Tabela 2, apenas o estudo do Couto, et al. 2016, relatou uma interação negativa referente a cicatrização após o uso do SB. Portanto, todos os outros estudos mostram que não houve interferência no reparo tecidual e indo de acordo com os estudos clínicos, mostrando que o uso do SB é seguro para hemostasia sem prejudicar no reparo tecidual. 


\section{Discussão}

Os riscos de hemorragias primária ou secundária, estão sempre presentes em cirurgias odontológicas periodontais. Essa revisão de literatura visa o estudo do subgalato de bismuto como agente hemostático e sua repercussão sobre o reparo tecidual.

O SB utilizado via oral tem como características o alívio do odor das fezes e flatulência em pacientes submetidos à cirurgia bariátrica e com Síndrome do Intestino irritável. Quando utilizado topicamente, auxilia nos casos de eczemas, queimaduras, escoriações, feridas e tratamentos de hemorroidas (Subgalato de Bismuto, 2016). Como anticoagulante aplicado topicamente, ele ativa o Fator XII acelerando a via intrínseca da cascata de coagulação (Thorisdottir et al., 1988; Kim et al., 2010).

A utilização do SB, como agente hemostático em regiões do palato, tem sido demonstrada nos estudos em animais (Kim et al., 2010; Luzzi et al., 2018) e humanos (Kim et al., 2010), não demonstrando clinicamente qualquer repercussão negativa no reparo tecidual. Assim, o SB pode ser uma opção hemostática na área palatina quando realizados enxertos gengivais livres. Uma análise histológica realizada num estudo com animais, demonstrou haver um retardo no reparo tecidual após o uso do SB (Couto et al. 2016). Quando mensurado o potencial inflamatório e cicatricial do SB em feridas criadas na conjuntiva e esclera ocular de ratos, a resposta inflamatória e o reparo foram reduzidos, ao passo que a reação de corpo estranho e a neovascularização ocorreram afastadas da área da ferida (Kawakami et al., 2014). No entanto, o SB foi efetivo no controle da hemorragia não demonstrando efeitos tóxicos sobre esses tecidos (Kawakami et al., 2014).

O número de estudos clínicos com a utilização tópica do SB é baixo (Manterola \& Smerilli, 2007; Kim et al., 2010). A mesma escassez se observa quando avaliados os casos clínicos (Pires et al., 2016). Apesar de não ter sido o foco principal do estudo, Manterola e Smerilli (2007), notaram boa evolução clínica após utilização do SB em pacientes com alterações na coagulação, evitando hemorragias no pós-operatório. Kim e colaboradores (2010), observaram não haver uma influência do SB sobre o reparo tecidual em áreas palatinas, indo de acordo com Pires e co-autores (2016), que relataram não haver complicações pós operatórias com a utilização do SB. No estudo de Puia (2020), 240 pacientes anticoagulados foram submetidos a extrações dentárias, tendo 80 pacientes cada um dos grupos selecionados aleatoriamente, dentre os três agentes hemostáticos usados na sua pesquisa apenas o subgalato de bismuto não apresentou complicação pós-operatória. O pó de SB foi misturado à solução fisiológica na proporção de $0,5 \mathrm{~g}$ de $\mathrm{SB}$ a cada $0,3 \mathrm{ml}$ de líquido, obtendo uma pasta para preencher o alvéolo. Resultados semelhantes em casos do uso do SB em extração dentária também foram reportadas em outros estudos (Loya et al. 2003; Baldelomar Carballo, Guerrero Petterson 2020).

Em um estudo in vitro, avaliando a citotoxicidade do SB em fibroblastos cutâneos, foi observado que em concentrações de $0,25 \mu \mathrm{g} / \mathrm{ml}$ houve um aumento da viabilidade celular, e nas concentrações maiores que $2 \mu \mathrm{g} / \mathrm{ml}$ não houve qualquer tipo de citotoxicidade (Lin, Liu \& Tsai, 2015). O mesmo estudo avaliou a migração celular in vitro na presença do SB e verificou que as concentrações de 0,5 e $1 \mu \mathrm{g} / \mathrm{ml}$ de SB permitiram a migração celular, porém a concentração $0,25 \mu \mathrm{g} / \mathrm{ml}$ inibiu a migração em relação ao controle deste experimento, sugerindo pouca toxicidade do SB sob as células testadas (Lin et al., 2015). Os resultados, mesmo sendo em fibroblastos cutâneos demostram segurança na utilização do SB. Futuros estudos in vitro analisando fibroblastos gengivais podem contribuir também na compreensão e eventuais testes de toxicidade do SB nos tecidos bucais. Outras aplicações poderiam ser realizadas, como também a influência sobre fibroblastos provenientes da polpa dentária que podem futuramente surgir novas formas de utilização do SB na prática clínica, como na proteção do complexo dentino-pulpar em casos de hemorragias pulpares ou em pulpites.

Estudos em animais demonstram que o SB não apresenta influência no reparo tecidual (Tramontina et al., 2002; Puia, Renou, Rey, Guglielmotti, \& Bozzini, 2009; Kim et al., 2012; Lima, Sampaio, Seidel, Branco \& Sobreiro, 2016; Dos Santos, Sampaio, de Moraes \& de Lima 2016; Luzzi et al., 2018), seja em tecidos moles (Tramontina et al., 2002; Kim et al., 2012; 
Lima et al., 2016; Dos Santos et al., 2016; Luzzi et al. ,2018), ou duros (Puia, Renou, Rey, Guglielmotti \& Bozzini, 2009). Entretanto, Couto e co-autores 2016 demonstraram que o uso do SB retardou a taxa de formação de novos vasos e a cicatrização das feridas sendo, até o momento, a única evidência de alteração da cicatrização após o uso intraoral desse composto.

A influência no reparo tecidual cutâneo foi avaliada em dorso de ratos (Lima et al., 2016; dos Sant os et al., 2016). Como resultado, os autores concluíram que o SB não interferiu no processo de reparo nas lesões cutâneas. Entretanto, apesar das divergências no comportamento celular cutâneo para as células da mucosa bucal, tais estudos podem sugerir uma futura utilização do SB na região extra-oral, como decorrentes em lesões provenientes de traumatismo, podendo ser o foco de futuros estudos clínicos.

Diante das limitações dessa pesquisa, vale salientar a escassez de estudos clínicos randomizados bem delineados. Não foi encontrado qualquer estudo comparando o SB com o cimento cirúrgico ou outro agente hemostático protetor da área doadora palatina, o que dificulta configurar a superioridade frente a outras formas de tratamento, como a sua aplicabilidade na área de Periodontia. Novos estudos com acompanhamento clínico com tempo maior, avaliações histológicas do reparo tecidual visando são necessárias visando a aplicabilidade desse composto, para que se sejam desenvolvidos protocolos clínicos que favoreçam a sua reprodução na prática clínica.

\section{Conclusão}

Diante das evidências que a literatura reporta até o momento, é sugerido a utilização na odontologia do SB com ação hemostática tanto em áreas doadoras palatais quanto em alvéolos após extrações dentárias. Vale salientar que a sua utilização em procedimentos cirúrgicos não exerce influência negativa sobre o reparo tecidual. Entretanto, mais estudos clínicos devem ser realizados para obtenção de protocolos clínicos de utilização do SB visando a otimização dos resultados nas diversas cirurgias odontológicas.

Como perspectivas futuras, sugere-se novos estudos que avaliem a influência da proporção de agente hemostático (SB) e sua diluição e toxicidade em diferentes tipos de solventes (como em soro físiológico ou substâncias vasoconstritoras), a aplicabilidade extra oral e em outros tecidos dentários (como o tecido pulpar), podendo permitir a expansão de seu uso em outras áreas da Odontologia.

\section{Agradecimentos}

O presente trabalho foi realizado com apoio da Fundação Universidade Federal de Mato Grosso do Sul - UFMS/MEC - Brasil.

\section{Referências}

Arroyo Júnior, P. C., Silva, R. D. C. M. A. D., Santi Neto, D. D., Santana Júnior, D. D., Ferreira, F. D., \& Silva, R. F. D. (2004). Uso do subgalato de bismuto para hemostasia local em hepatectomias parciais em ratos. Revista do Colégio Brasileiro de Cirurgióes, 31, $165-171$.

Baldelomar Carballo, K. E., \& Guerrero Petterson, J. D. L. A. (2020). Eficacia del subsalicilato y subgalato de bismuto como agentes hemostáticos después de la extracción quirúrgica de terceros molares en pacientes atendidos en el Hospital Amistad Japón-Nicaragua, Granada, durante el segundo semestre 2019 (Doctoral dissertation, Universidad Nacional Autónoma de Nicaragua, Managua).

Barbosa, L. M., da Silva, M. S. A., Cavalcanti, A. M. F., de Melo Nogueira, L. D., Francisco, M. A., de Morais Santos, M. P., ... \& Laureano Filho, J. R. (2020). Protocolo de tratamento cirúrgico de pacientes em uso de anticoagulante e antiagregante plaquetário. Research, Society and Development, 9(9), e670997726e670997726.

Brasileiro, H. M., Lee, I. W., Rapport, A. (2006). "Uso do subgalato de bismuto como agente hemostático em tonsiléctomia palatina: estudo de 201 casos", ACTA ORL/Técnicas em Otorrinolaringologia. São Paulo: Atha, p. 181-5.

Couto, E. V., Ballin, C. R., Sampaio, C. P. P., Maeda, C. A. S., Ballin, C. H., Dassi, C. S., \& Yukari Miura, L. (2016). Experimental study on the effects of bismuth subgallate on the inflammatory process and angiogenesis of the oral mucosative Brazilian journal of otorhinolaryngology, 82, 17-25. 
Cozzi, L. M., Megerian, C. A., Dugue, C., Barcello, M., Abdul-Karim, F. W., Arnold, J. E., \& Maniglia, A. J. (1992). Pulmonary sequelae of intraparenchymal bismuth subgallate. The Laryngoscope, 102(6), 597-599.

de Campos, N., Furlaneto, F., e Buischi, Y. D. P. (2019). Contemporary Applications of Biologic Hemostatic Agents across Surgical Specialties: Bleeding in Dental Surgery. In Contemporary Applications of Biologic Hemostatic Agents across Surgical Specialties-Volume 2. IntechOpen.

de Sousa Pinheiro, E., Veloso, K. M. M., de Andrade, S. M., \& de Oliveira, E. H. (2021). Efetividade do ácido tranexâmico em pacientes sistemicamente comprometidos na odontologia: Revisão integrativa. Research, Society and Development, 10(7), e3110716119-e3110716119.

Dos Santos, R. M. F., Sampaio, C. P. P., de Moraes, D. P., \& de Lima, R. L. (2016). Evaluation of the effects of bismuth subgallate on wound healing in rats. Histological findings. International archives of otorhinolaryngology, 20(04), 377-381.

Dym, H., \& Ogle, O. E. (2004). Atlas de cirurgia oral menor. Livraria Santos Editora.

Holck, D. E., Foster, J. A., Dutton, J. J., \& Dillon, H. D. (1999). Hard palate mucosal grafts in the treatment of the contracted socket. Ophthalmic plastic and reconstructive surgery, 15(3), 202-209.

Kawakami, P. A., Velez-Montoya, R., Castillejos-Chevez, A., Remolina, A., Garcia-Aguirre, G., Rodriguez-Reyes, A., \& Salcedo, G. (2014). Safety and efficacy of bismuth subgallate as an hemostatic agent in an animal experimental model. Investigative Ophthalmology \& Visual Science, 55(13), 1510-1510.

Kim, S. H., Tramontina, V. A., Papalexiou, V., \& Luczyszyn, S. M. (2010). Bismuth subgallate as a topical hemostatic agent at palatal donor sites. Quintessence International, 41(8)

Kim, S. H., Tramontina, V. A., Papalexiou, V., Luczsyzyn, S. M., De Lima, A. A. S., \& Do Prado, A. M. B. (2012). Bismuth subgallate as a topical haemostatic agent at the palatal wounds: a histologic study in dogs. International journal of oral and maxillofacial surgery, 41(2), 239-243.

Levine, M. N., Raskob, G., Landefeld, S., \& Hirsh, J. (1995). Hemorrhagic complications of anticoagulant treatment. Chest, 108(4), 276S-290S.

Lima, R. L. D., Sampaio, C. P., Seidel, K. C., Branco, M., \& Sobreiro, R. M. (2016). Avaliação dos efeitos do subgalato de bismuto na proliferação de miofibroblastos. Jornal Vascular Brasileiro, 15, 210-216.

Lin, C. Y., Liu, Y. F., \& Tsai, Y. C. (2015). Differential Effects on Fibroblast Cells Proliferation and Migration by Bismuth Subgallate and Borneol Individual and Combination. International Journal of Pharmacology.

Liu, L., Rodman, C., Worobetz, N. E., Johnson, J., Elmaraghy, C., \& Chiang, T. (2019). Topical biomaterials to prevent post-tonsillectomy hemorrhage. Journal of Otolaryngology-Head \& Neck Surgery, 48(1), 1-17.

Loya, T. A. M., Fandiño, J. J. T., \& Sierra, J. S. M. (2003). Eficacia y seguridad de la aplicación de subgalato y subsalicilato de bismuto como agentes hemostáticos después de la extracción quirúrgica de terceros molares. Revista de la Asociación Dental Mexicana, 60(3), 90-94.

Luzzi, T., Adilson, A., de Lima, S., Augusto, V., Papalexiou, V., Mara, S., ... \& Martinez, A. Lucinara Ignez (2018). "Use of fibrinolisin / deoxyribonuclease and bismutal subgalate in wound palatine mucosa repair. Histological study in rats", Paripex-Indian Journal of Research, 7(6).

Manterola, E. R., \& Smerilli, A. L. (2007). Uso del subgalato de bismuto como técnica hemostática en la exodoncia para pacientes dializados. Rev Fac Odontol (UBA), 22, 52-5325.

Mendes, K. D. S., Silveira, R. C. D. C. P., \& Galvão, C. M. (2008). Revisão integrativa: método de pesquisa para a incorporação de evidências na saúde e na enfermagem. Texto \& contexto-enfermagem, 17, 758-764.

O'Neil, M. J., Smith, A., Heckelman, P. E., \& Budavari, S. (2001). The merck index-An encyclopedia of chemicals, drugs, and biologicals. whitehouse station, NJ: Merck and Co. Inc, 767, 4342.

Peterson, L. J. (2000). Cirurgia oral e maxilofacial contemporânea. In Cirurgia oral e maxilofacial contemporanea (pp. 772-772).

Pires, W. R., Mota, M. O., Mizuno, E. H. F., \& Mizuno, L. T. (2016). Subgalato de bismuto atuando como agente hemostático pós exérese de hiperplasia papilomatosa. Rev. Odontol. Araçatuba (Online), 25-29.

Puia, S. A., Hilber, E. M., \& Garcia-Blanco, M. (2020). Randomized Clinical Trial Comparing Three Local Hemostatic Agents for Dental Extractions in Patients under Chronic Anticoagulant Therapy - A Comparative Study. Annals of maxillofacial surgery, 10(2), $292-296$.

Puia, S. A., Renou, S. J., Rey, E. A., Guglielmotti, M. B., \& Bozzini, C. E. (2009). Effect of bismuth subgallate (a hemostatic agent) on bone repair; a histologic, radiographic and histomorphometric study in rats. International journal of oral and maxillofacial surgery, 38(7), 785-789.

Quintero Parada, E., Sabater Recolons, M. D. M., Chimenos Kustner, E., \& López López, J. (2004). Hemostasia y tratamiento odontológico. Avances en Odontoestomatología, 20(5), 247-261.

Sampognaro, P., Vo, K. T., Richie, M., Blanc, P. D., \& Keenan, K. (2017). Bismuth Subgallate toxicity in the age of online supplement use. The neurologist, 22(6), 237-240

Subgalato De Bismuto (2016). Iberoquímica Magistral. Bula de remédio, 2016.

Tramontina, V. A., Machado, M. A. N., Filho, G. D. R. N., Kim, S. H., Vizzioli, M. R., \& Toledo, S. (2002). Effect of bismuth subgallate (local hemostatic agent) on wound healing in rats. Histological and histometric findings. Brazilian dental journal, 13(1), 11-16.

Thorisdottir, H., Ratnoff, O. D., \& Maniglia, A. J. (1988). Activation of Hageman factor (factor XII) by bismuth subgallate, a hemostatic agent. The Journal of laboratory and clinical medicine, 112(4), 481-486. Manterola, E. R., \& Smerilli, A. L. (2007). Uso del subgalato de bismuto como técnica hemostática en la exodoncia para pacientes dializados. Rev Fac Odontol (UBA), 22, 52-5325. 